\title{
ESTUDO MORFOLOGICO DE SCHISTOSOMA MANSONI PERTENCENTES A LINHAGENS DE BELO HORIZONTE (MG) E DE SÃO JOSÉ DOS CAMPOS (SP)
}

\begin{tabular}{|l|} 
RSPU-B/180 \\
\hline
\end{tabular}

Magalhães, L. A. \& Carvalho, J. F. de - Estudo morfológico de Schistosoma mansoni pertencentes a linhagens de Belo Horizonte (MG) e de São José dos Campos (SP). Rev. Saúde públ., S. Paulo, 7: 289-94, 1973.

Resumo: Foram estudados morfologicamente exemplares de $\mathrm{S}$. mansoni adultos das linhagens de Belo Horizonte (MG), e de São José dos Campos (SP), Brasil. Concluiu-se haver diferenças significativas referentes às medidas de comprimento do verme, distância entre as ventosas oral e acetabular, distância entre a parte anterior dos vermes $e$ a extremidade distal das gônadas e quanto ao número de testículos.

Unitermos: Schistosoma mansoni *; Esquistossomose *.

\section{I $N$ T R O D U C $\mathbb{A} O$}

Desde que Paraense \& CorrêA 1 (1963) assinalaram a existência de linhagens de $S$. mansoni vinculadas ao hospedeiro intermediário (Biomphalaria glabrata e $B$. tenagophila), outras publicações reforçaram a verificação dos autores.

Nesse trabalho estudamos a morfologia de adultos das linhagens acima referidas, com a finalidade de pesquisar diferenças morfológicas.

\section{MATERTAL E METODOS}

Infectamos camundongos com cercárias provenientes das linhagens de $S$. mansoni de Belo Horizonte (BH) e São José dos Campos (SJ). Os roedores foram sacrificados 60 dias após o banho infectante.

Os vermes colhidos por perfusão (Yolles et al. 2 , 1947) foram, após fixados, corados pelo carmim clorídrico e montados em lâminas.

Contamos o número de testículos e os ovos localizados no útero.

Foram anotadas quatro medidas:

Medida I - comprimento do verme.

Medida II - largura do verme à altura da segunda ventosa.

* Do Instituto de Biologia da Universidade Estadual de Campinas. - Caixa Postal 1170 Campinas, S.P. - Brasil.

* Do Instituto de Ciências Matemáticas de sāo Carlos. Universidade de Sáo Paulo. São Carlos, S.P. - Brasil. 
MAGALHAES, L. A. \& CARVALHo, J. F. de - Estudo morfológico de Schistosoma mansoni pertencentes a linhagens de Belo Horizonte (MG) e de Săo José dos Campos (SP). Rev. Saúde públ., S. Paulo, 7:289-94, 1973.

Medida III - distância do início da primeira ventosa ao início da segunda ventosa.

Medida IV - distância entre a parte anterior do verme e a extremidade distal das gônadas.

A fim de que as medidas pudessem ser tomadas, projetamos a imagem dos vermes através de um prisma montado sobre a ocular do microscópio, em um anteparo sobre o qual os helmintos eram desenhados e posteriormente medidos com curvímetro. Em alguns exemplares, não sendo a projeção suficientemente nitida, as medidas eram tomadas através de câmara clara.

Em cada variável estudada, procuramos verificar se as linhagens diferiram estatisticamente, para melhor caracterizá-las.

Com a finalidade de evitar pressuposições sobre a distribuição de cada variável, empregamos o teste de Mann Whitney nas seguintes hipóteses:

$\mathrm{H}_{0}=\mathrm{a}$ variável $\chi$ é igualmente distribuída nas duas linhagens;

$\mathrm{H}_{1}=$ as distribuições de $\chi$ são diferentes nas duas linhagens;

onde $\chi$ é uma qualquer das variáveis estudadas.

Os testes foram feitos separadamente para machos e fêmeas em razão do acentuado dimorfismo sexual.

Todas as conclusões foram tomadas ao nível de significância de 0,05 .

$$
\text { R E S U L T A D O S }
$$

Os resultados estão contidos nas $\mathrm{Ta}$ belas 1, 2, 3, 4 .
Ao examinarmos o aparelho reprodutor dos vermes, verificamos que vários deles não haviam alcançado seu completo desenvolvimento. Dados referentes a esses vermes foram colocados à parte na Tabela 3.

Com referência ao número de ovos encontrados no útero dos vermes examinados, encontramos a média de 1 ovo por fêmea para as duas linhagens.

O número de testículos está assinalado ña Tabela 4.

\section{COMENTARIOS E CONCLUSÓES}

Analisando estatisticamente os resultados contidos nas Tabelas 1 e 2 verificamos que com referência à largura dos vermes machos e fêmeas, aceita-se a hipótese de igualdade para as linhagens de SJ e BH. Verificamos que, em média, os vermes machos e fêmeas de BH são estocasticamente mais longos do que os de $\mathrm{SJ}$.

Rejeita-se a hipótese de igualdade entre as linhagens estudadas no que tange à distância do início da primeira ventosa, ao início da segunda ventosa nos vermes machos e aceita-se esta hipótese para as fêmeas.

A distância entre a parte anterior do verme e a extremidade distal das gônadas diferiu significativamente em ambos os sexos.

Analisando os dados contidos na Tabela 2 verificamos que, estatiscamente, $o$ número de testículos dos exemplares de S. mansoni de $\mathrm{BH}$ é maior do que nos exemplares de $\mathbf{S J}$. 
MAGALHAES, L. A. \& CARVALHO, J. F. de - Estudo morfológico de Schistosoma mansoni pertencentes a linhagens de Belo Horizonte (MG) e de São José dos Campos (SP). Rev. Saúde puibl., S. Paulo, 7:289-94, 1973.

T A B E L A 1

Medidas em milimetros dos Schistosoma mansoni da linhagem de Belo Horizonte, MG.

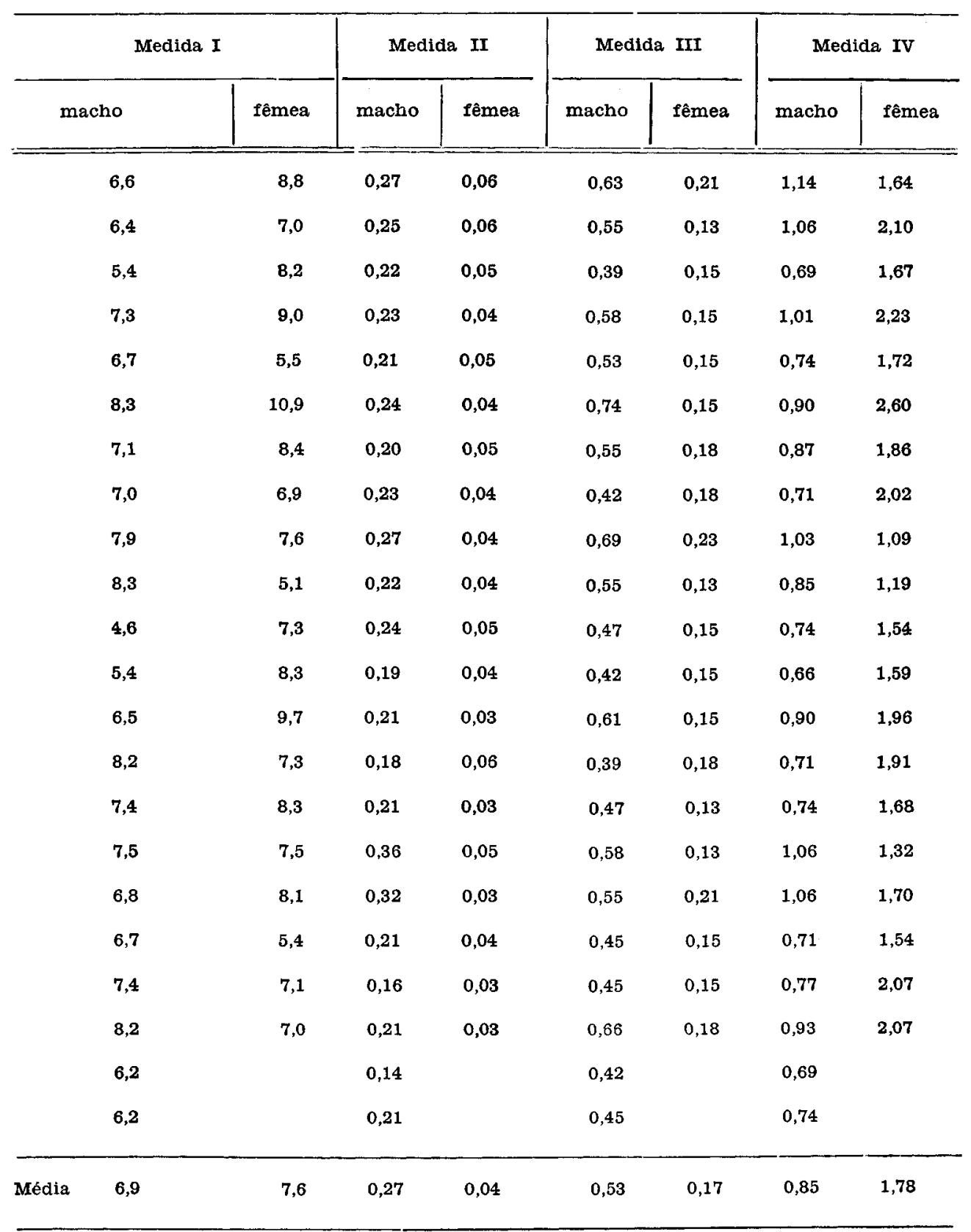


MAGALHAES, L. A. \& CARVALHO, J. F. de - Estudo morfológico de Schistosoma mansoni pertencentes a linhagens de Belo Horizonte (MG) e de São José dos Campos (SP). Rev. Saúde puibl., S. Paulo, 7:289-94, 1973.

T A B E L A 2

Medidas em milímetros dos Schistosoma mansoni da linhagem de São José dos Campos, SP.

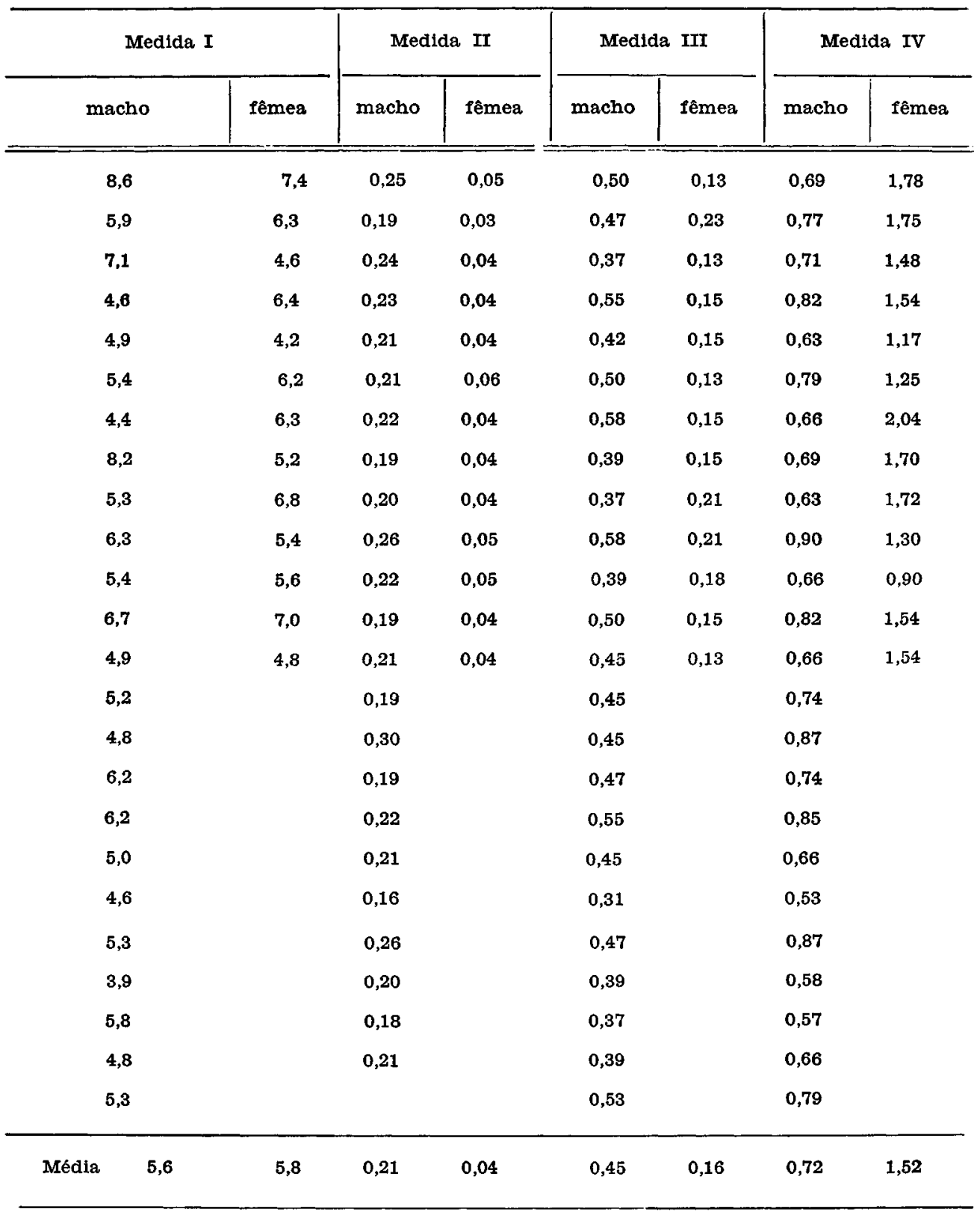


MAGALhAES, L. A. \& CARVALHO, J. F. de - Estudo morfológico de Schistosoma mansoni pertencentes a linhagens de Belo Horizonte (MG) e de São José dos Campos (SP). Rev. Saúde públ., S. Paulo, 7:289-94, 1973.

\section{T A B E L A 3}

Comprimento em milímetros dos vermes que apresentaram aparelho reprodutor não desenvolvido.

\begin{tabular}{|c|c|c|c|c|c|}
\hline & São José & Média & Belo & Horizonte & Média \\
\hline $\begin{array}{l}\text { Macho } \\
\text { Fêmea }\end{array}$ & $\begin{array}{l}2,3 ; 3,2 \\
3,0 ; 3,0 ; 3,4 ; \\
3,7 ; 3,9 ; 2,9 ; \\
2,8 ; 2,8 ; 2,0\end{array}$ & 2,75 & $\begin{array}{l}\text { Macho } \\
\text { Fêmea }\end{array}$ & $\begin{array}{llll}3,1 ; & 4,3 ; & 3,5 & \\
1,9 ; & 3,9 ; & 3,2 ; & 3,4 ; \\
3,1 ; & 4,8 ; & 3,3 ; & 3,5 ; \\
3,0 ; & 3,0 ; & 2,6 ; & 2,6 ; \\
3,4 ; & 2,9 ; & 2,5 ; & 3,4 ; \\
2,9 ; & 3,8 ; & 3,3 ; & 3,2 ; \\
2,4 & & & \end{array}$ & 3,63 \\
\hline
\end{tabular}

T A B E L A 4

Número de testículos de $S$. mansoni de linhagens de Belo Horizonte e de São José dos Campos

\begin{tabular}{|c|c|c|c|c|c|}
\hline \multicolumn{3}{|c|}{$\begin{array}{l}\text { Linhagem de } \\
\text { Belo Horizonte }\end{array}$} & \multicolumn{3}{|c|}{$\begin{array}{c}\text { Linhagem de } \\
\text { São José dos Campos }\end{array}$} \\
\hline 9 & 8 & 10 & 9 & 6 & 7 \\
\hline 8 & 8 & 9 & 6 & 6 & 7 \\
\hline 9 & 8 & 5 & 9 & 8 & 6 \\
\hline 11 & 8 & 9 & 7 & 6 & 7 \\
\hline 9 & 8 & 8 & 7 & 7 & 9 \\
\hline 8 & 9 & 8 & 5 & 7 & 6 \\
\hline 6 & 8 & 9 & 6 & 9 & 5 \\
\hline 9 & 7 & 12 & 9 & 9 & 7 \\
\hline 10 & 7 & 7 & 9 & 8 & 6 \\
\hline 10 & 8 & 9 & 8 & 6 & 8 \\
\hline 7 & 8 & 10 & 10 & 8 & 5 \\
\hline 6 & 9 & 9 & 7 & 6 & \\
\hline 10 & 8 & 9 & 7 & 7 & \\
\hline 6 & 11 & 8 & 7 & 7 & \\
\hline 7 & 9 & 7 & 7 & 7 & \\
\hline 10 & 9 & 7 & 6 & 7 & \\
\hline 8 & 10 & 8 & 7 & 7 & \\
\hline 8 & 7 & 8 & 7 & 10 & \\
\hline 8 & 10 & 9 & 8 & 7 & \\
\hline 9 & 8 & 8 & 7 & 8 & \\
\hline 9 & 8 & 5 & 7 & 4 & \\
\hline 8 & 8 & 7 & 6 & 8 & \\
\hline 8 & 7 & 9 & 7 & 5 & \\
\hline 7 & 9 & & 8 & 6 & \\
\hline 10 & 8 & & 6 & 5 & \\
\hline 10 & 7 & & 12 & 6 & \\
\hline 10 & 9 & & 9 & 7 & \\
\hline 8 & 7 & & 8 & 7 & \\
\hline 8 & 6 & & 7 & 8 & \\
\hline 10 & 6 & & 5 & 6 & \\
\hline Méd & .8 & & Média & 7,1 & \\
\hline
\end{tabular}


MAGAlHAES, L. A. \& CARVALHo, J. F. de - Estudo morfológico de Schistosoma mansont pertencentes a linhagens de Belo Horizonte (MG) e de São José dos Campos (SP). Rev. Saúde públ., S. Paulo, 7:289-94, 1973.

\section{RSPU-B/180}

Magalhães, L. A. \& CARvalho, J. F. de - [Morphologic studies of Schistosoma mansoni strains from Belo Horizonte MG and S. José dos Campos, SP (Brazil).] Rev. Saúde públ., S. Paulo, 7: 289-94, 1973.

Summary: Two strains of Schistosoma mansoni (Belo Horizonte, MG and S. José dos Campos, SP, Brazil) are morphologically studied. Some numerical characteristics are found to be different between the strains. These differences are as follows: lenght, distance from the oral sucker until the ventral sucker, distance between the anterior pole of the worm and the distal part of the gonads and finally the number of testes.

Uniterms: Schistosoma mansoni *; Schistosomiasis *

\section{REFERENCIAS BIBLIOGRAFICAS}

1. PARAENSE, W. L. \& CORREA, L. R. Sobre a ocorréncia de duas raças biológicas do Schistosoma mansoni no Brasil. Ciên. e Cult., 15:234-46. 1963.
2. YOLLES, T. K. et al. - A technique for the perfusion of laboratory animals for the recovery of schistosomoses. J. Parasit., 33:419-26, 1947.

Recebido para publicação em 15-6-1973 Aprovado para publicação em 10-7-1973 